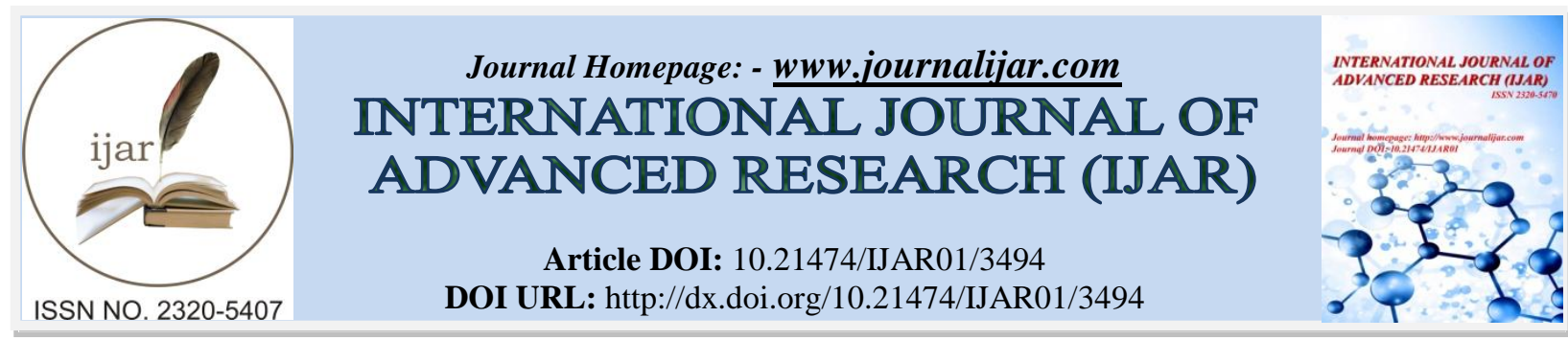

RESEARCH ARTICLE

\title{
ASSESSMENT OF SPIROMETRY IN GASTROESOPHAGEAL REFLUX DISEASE(GERD) ASSOCIATED ASTHMA PATIENTS.
}

\section{Ahmed Hamouda Arnaout ${ }^{1}$ and Ashraf El Sayed Selim ${ }^{2}$.}

1. Department of Internal Medicine, Faculty of Medicine, Zagazig University, Egypt.

2. Department of Chest diseases, Faculty of Medicine, Zagazig University, Egypt.

\section{Manuscript Info}

Manuscript History

Received: 09 January 2017

Final Accepted: 07 February 2017

Published: March 2017

Key words:-

Gastroesophageal Reflux Disease,

chronic cough, asthma.

\section{Abstract}

Introduction: Gastroesophageal reflux disease (GERD) can cause several esophageal complications, as esophagitis, ulceration, stricture, hemorrhage, and Barrett's esophagus. Though, the associated problems with GERD have expanded to extra esophageal sites. Chronic cough and asthma are two clinical problems caused or triggered by GERD. Spirometric changes among GERD associated cough and asthma still a topic of ongoing research.

Aim of the study: to assess the spirometric parameters of GERD associated cough and asthma patients in relation to different clinical aspects of the disease including body mass index (BMI), disease duration, presence or absence of symptoms as well as endoscopic findings.

Patients and methods: 90 subjects of either sex with a mean age of $40.5 \pm 12$ year are included in the study, 55 GERD associated cough and asthma patients served as test group while the remaining 35 subjects served as control group, each patient, each patient underwent spirometry and gastric endoscopy during the period from September 2015 to March 2016.

Results: Spirometric data of the control group were within the normal predicted range (80-120\%) thus excluding the possibility of any asymptomatic obstructive airway disease. Whereas, the measured spirometric parameters (forced vital capacity (FVC), forced expiratory volume in 1 second ratio (FEV1\%), peak expiratory flow (PEF), and forced mid expiratory flow(FMF) are significantly reduced in the test group with a clear restrictive pattern among the overweight subjects. Furthermore, neither the presence nor duration of symptoms affected the spirometric picture of the GERD associated cough and asthma subjects, unlike those with positive endoscopy findings who revealed significant obstructive pattern when compared to those with negative endoscopy findings.

Conclusions: GERD associated cough and asthma patients with positive endoscopy findings showed obstructive pattern of spirometry irrelevant to the presence or absence of symptoms or duration of the disease.

Copy Right, IJAR, 2017,. All rights reserved. 


\section{Introduction:-}

Gastroesophageal reflux disease (GERD) is a condition that develops when the reflux of stomach contents causes troublesome symptoms and/or complications (1). The true prevalence of GERD in the population is underestimated and the disease is often misdiagnosed. Approximately $20-40 \%$ of the adult populations in Western countries suffer from heartburn and/or regurgitation that have a negative impact on the patient's daily activities, sleep and working life, irrespective of the presence or absence of esophagitis (2,3). According to the Montreal Definition of GERD, concomitant gastroesophageal reflux symptoms is "aggravating factor" to extraesophageal symptoms and lesions like reflux cough, reflux laryngitis and viewed as an reflux asthma (4). Gastroesophageal reflux is a potential trigger of asthma. Approximately 77\% of asthmatics report heartburn (5). There is a cause effect relationship between asthma and gastroesophageal reflux which can turn into a vicious cycle (6).

The basic motivation behind conducting the present work was an attempt to answer the questions: Can GERD cause an abnormal spirometry test? An issue of ongoing research.

\section{Patients and Methods:-}

Ninety adult patients of either sex aged $40.5 \pm 12$ years (19-65years) included in this study, from whom a written consent plus data sheet, including all necessary personal and health information were obtained.

\section{They were classified as:-}

(A) Control group: included 35 apparently healthy subjects recruited from patient companions, relatives, and friends in addition to hospital health staff workers after fulfilling the following criteria:

1. Never smokers.

2. No history of any significant pulmonary or cardiac diseases.

3. Clear chest on physical examination.

4. Absence of any musculoskeletal, neuromuscular disorders, or any other condition which could affect spirometry test.

(B) Test group: included 55 patients with gastro-esophageal reflux disease associated cough and/or asthma approved by history, clinical examination and other necessary investigations.

Patients were selected from outpatient subjects referred to the Endoscopy Unit and Pulmonary Function Units, during the period from September 2015 to March 2016.

Table 1, shows the distribution and clinical data of the test group.

Table 1:- Distribution and clinical data of the test group.

\begin{tabular}{|c|c|c|c|c|c|c|c|}
\hline \multicolumn{2}{|c|}{ BMI } & \multicolumn{2}{c|}{ GERD Symptoms } & \multicolumn{2}{c|}{ GERD duration } & \multicolumn{2}{c|}{ Endoscopy } \\
\hline $\begin{array}{c}\text { Normal } \\
\text { body wt } \\
\begin{array}{c}\text { BMI (19- } \\
25)\end{array}\end{array}$ & $\begin{array}{c}\text { Over body } \\
\text { wt } \\
\text { BMI }>25\end{array}$ & Present & Absent & $<3$ months & $>6$ months & Negative & Positive \\
\hline $\mathrm{N}=14$ & $\mathrm{~N}=41$ & $\mathrm{~N}=40$ & $\mathrm{~N}=15$ & $\mathrm{~N}=21$ & $\mathrm{~N}=34$ & $\mathrm{~N}=18$ & $\mathrm{~N}=37$ \\
\hline
\end{tabular}

Anthropometric measurements: Height, weight were measured using standard techniques as follows: height to within $0.5 \mathrm{Cm}$, without shoes; Weight to within $100 \mathrm{~g}$, without heavy clothing (table 2). Body mass index (BMI) was calculated by the following

Formula:-

$\mathrm{BMI}=$ Weight $(\mathrm{kg}) /[\text { Height }(\mathrm{m})]^{2}(7)$.

Table 2:- Demographic and anthropometric data of the studied groups.

\begin{tabular}{|c|c|c|c|c|c|c|}
\hline \multirow{2}{*}{ Parameter } & \multicolumn{3}{|c|}{ Control group (N=35) } & \multicolumn{3}{c|}{ Test group (N=55) } \\
\cline { 2 - 7 } & Minimum & Maximum & Mean \pm SD & Minimum & Maximum & Mean \pm SD \\
\hline Age (year) & 19 & 58 & $39 \pm 11$ & 20 & 65 & $42 \pm 13$ \\
\hline Height (m) & 1.6 & 1.86 & $1.68 \pm 0.06$ & 1.47 & 1.80 & $1.64 \pm 0.08$ \\
\hline Weight (Kg) & 49.5 & 98.5 & $75.3 \pm 13$ & 52.8 & 117.5 & $87.7 \pm 19.45$ \\
\hline BMI & 18.6 & 33 & $24.2 \pm 5.27$ & 17.9 & 42 & $28.2 \pm 6.14$ \\
\hline
\end{tabular}


Spirometry: percent predicted forced vital capacity (FVC), forced expiratory volume in 1 second (FEV1\% ) ratio, peak expiratory flow (PEF), and the forced mid expiratory flow (FMF) were measured using computer based spirometer. Standard procedure was adopted following the recommendations of the American Thoracic Society (ATS) (8).

The forced expiratory vital capacity procedure was described and demonstrated to the subjects before the test while encouraging breathing out as long and forcefully as possible. The best of three technically satisfactory maneuvers was recorded.

Statistical analysis: The data obtained in the study were analyzed using the SPSS statistics for data analysis. Standard statistical methods were used to determine the mean and standard deviation. Descriptive data analysis was used to describe different variables in addition to the Independent Sample T-test to compare different means.

\section{Results:-}

The percentage predicted spirometric values of the control and test groups shown in (table 3 ). The healthy control group is within the normal predicted range (80-120\%) regarding all measured spirometric values, unlike the test group who showed highly significant reduction in the FEV1\%, PEF and FMF (p < 0.01) revealing a clear obstructive airway pattern in addition to a significant reduction in FVC (restrictive index, $\mathrm{p}<0.05$ ).

Table (4) compares the percentage predicted spirometric parameters between normal body weight and overweight groups. The overweight group showed significant reduction in the $\mathrm{FVC}$ as compared to the normal weight group (P $<0.05)$ while other spirometric parameters (FEV1\%, PEF and FMF) does not show significant difference.

Table (5) compares the percentage predicted spirometric parameters between asymptomatic and symptomatic GERD groups. All measured spirometric parameters (FVC, FEV1\%, FPEF and FMF) were not found to be significantly different between the two groups.

Table (6) shows the percentage predicted spirometric parameters when compared between the test groups with short duration of GERD symptoms, less than 3 months and those with longer than 3 months duration of GERD symptoms. No significant differences were found between the two groups regarding again all measured spirometric parameters.

Table (7) shows the spirometric parameters within the test group with negative endoscopic findings as compared with those of positive endoscopic findings for GERD. No significant difference was observed regarding the FVC while there is a statistically significant reduction in the FEV1\%, FMF $(\mathrm{p}<0.01)$ and PEF (p < 0.05) among the group with positive endoscopic finding.

Table 3:- Comparison of the spirometric parameters between test and control groups.

\begin{tabular}{|c|c|c|c|}
\hline \multirow{2}{*}{$\begin{array}{c}\text { Parameter }(\% \\
\text { predicted })\end{array}$} & \multicolumn{2}{|c|}{ Mean \pm SD (minimum-maximum) } & \multirow{2}{*}{ P value } \\
\cline { 2 - 4 }$n$ & Control group $(\mathrm{n}=35)$ & Test group $(\mathrm{n}=55)$ & $<0.05$ \\
\hline FVC & $99.76 \pm 9.35(80.8-115.5)$ & $93.66 \pm 15.44(50.1-101.0)$ & $<0.01$ \\
\hline FEV1\% & $89.56 \pm 8.51(82.3-116)$ & $82.22 \pm 17.41(41.5-91.08)$ & $<0.01$ \\
\hline PEF & $96.69 \pm 11.84(84.7-118.8)$ & $68.93 \pm 18.86(41.2-83.02)$ & $<0.01$ \\
\hline FMF & $90.11 \pm 10.21(82.8-119.9)$ & & \\
\hline
\end{tabular}

Table 4:- Comparison of Spirometric parameters between normal body weight and overweight groups.

\begin{tabular}{|c|c|c|c|}
\hline \multirow{2}{*}{ Parameter (\% predicted) } & \multicolumn{2}{|c|}{ Mean \pm SD } & \multirow{2}{*}{ P value } \\
\cline { 2 - 4 } & $\begin{array}{c}\text { Normal body weight (BMI } \\
=18.9-25) \mathrm{n}=14\end{array}$ & $\begin{array}{c}\text { Over body weight }(\mathrm{BMI}> \\
25) \mathrm{n}=41\end{array}$ & $\mathrm{P}<0.05$ \\
\hline FVC & $98.67 \pm(6.36)$ & $90.38 \pm(17.11)$ & $\mathrm{NS}$ \\
\hline FEV1\% & $71.10 \pm(10.18)$ & $72.23 \pm(11.54)$ & $\mathrm{NS}$ \\
\hline PEF & $84.69 \pm(13.99)$ & $81.64 \pm(18.01)$ & $\mathrm{NS}$ \\
\hline
\end{tabular}


Table 5:- Comparison of Spirometric parameters between asymptomatic and symptomatic GERD groups.

\begin{tabular}{|c|c|c|c|}
\hline \multirow{2}{*}{$\begin{array}{c}\text { Parameter } \\
\% \text { predicted })\end{array}$} & $\begin{array}{c}|c| \\
\text { Asymptomatic } \\
\text { GERD } n=15\end{array}$ & $\begin{array}{c}\text { Symptomatic } \\
\text { GERD n=40 }\end{array}$ & \multirow{2}{*}{ P value } \\
\hline FVC & $89.23 \pm(14.53)$ & $93.71 \pm(15.83)$ & NS \\
\hline FEV1\% & $77.31 \pm(11.62)$ & $75.93 \pm(9.02)$ & NS \\
\hline PEF & $82.93 \pm(15.7)$ & $80.56 \pm(15.56)$ & NS \\
\hline FMF & $64.94 \pm(14.97)$ & $63.93 \pm(13.27)$ & NS \\
\hline
\end{tabular}

Table 6:- Spirometric values of test group in respect to the duration of GERD symptoms.

\begin{tabular}{|c|c|c|c|}
\hline \multirow{2}{*}{$\begin{array}{c}\text { Parameter } \\
\% \text { predicted })\end{array}$} & \multicolumn{2}{|c|}{ Mean \pm SD } & \multirow{2}{*}{ P value } \\
\cline { 2 - 4 } & $\begin{array}{c}\text { GERD duration } \\
(<3 \text { months }) \mathrm{n}=21\end{array}$ & $\begin{array}{c}\text { GERD duration } \\
(>3 \text { months }) \mathrm{n}=34\end{array}$ & $\mathrm{NS}$ \\
\hline FVC & $91.12 \pm(18.12)$ & $93.34 \pm(12.51)$ & $\mathrm{NS}$ \\
\hline FEV1\% & $74.96 \pm(11.62)$ & $72.73 \pm(9.71)$ & $\mathrm{NS}$ \\
\hline PEF & $85.50 \pm(17.04)$ & $78.55 \pm(14.05)$ & $\mathrm{NS}$ \\
\hline
\end{tabular}

Table 7:- Spirometric values of test group in respect to endoscopic findings.

\begin{tabular}{|c|c|c|c|}
\hline \multirow{2}{*}{$\begin{array}{c}\text { Parameter } \\
\% \text { predicted) }\end{array}$} & $\begin{array}{c}\text { GERD } \\
\text { (negative endoscopy) } \\
\mathrm{n}=18\end{array}$ & $\begin{array}{c}\text { GERD } \\
\text { (positive endoscopy) } \\
\mathrm{n}=37\end{array}$ & \multirow{2}{*}{$\mathrm{P}$ value } \\
\hline FVC & $94.03 \pm(18.06)$ & $93.38 \pm(13.37)$ & $\mathrm{NS}$ \\
\hline FEV1\% & $84.79 \pm(8.95)$ & $73.07 \pm(11.39)$ & $\mathrm{P}<0.01$ \\
\hline PEF & $87.25 \pm(18.01)$ & $78.32 \pm(16.15)$ & $\mathrm{P}<0.05$ \\
\hline FMF & $84.07 \pm(18.51)$ & $57.21 \pm(7.23)$ & $\mathrm{P}<0.01$ \\
\hline
\end{tabular}

\section{Discussion:-}

When spirometric measurements were compared between the age and height matched studied groups (table 2), the GERD associated cough and asthma group with an overweight BMI (table1) showed significant reduction in all measured spirometric variables, signifying the growing body of evidence relating overweight and obesity with a wide range of health conditions including chronic obstructive lung disease (COPD) and asthma (9,10,11). While the test group further subgrouped on the basis of BMI in an attempt to rationalize the restrictive pattern, the results revealed significant reduction in the percentage predicted FVC $(\mathrm{p}<0.05)$ among the overweight group in respect to those with normal weight group (table 3); this finding has two implications, first, it could further confirm the fore mentioned relation between overweight and obstructive spirometric pattern, second, it can reinforce the role of gastroesophageal reflux in chronic cough and asthma(12).

Concerning the link between gastric acid reflux and respiratory symptoms (cough, dyspnea and wheezes), the test group was classified according to the presence of symptoms (symptomatic and asymptomatic) and to the duration of reflux symptoms into short duration ( $<3$ months) and long duration subgroups ( $>3$ months) (table 4 and 5). The obtained data (tables 4 and 5) of the nonsignificant differences in all measured spirometric values, revealing that neither the presence nor the duration of GERD symptoms could affect spirometry. These findings might be attributed to the control of acid reflux with medications for example, a proton pump inhibitor.

Consequently, the obstructive spirometric pattern (table 6) in the GERD subjects with positive endoscopic finding could be due to the effect of the acid reflux on the respiratory passageways. Though the cause-effect relationship between asthma and acid reflux isn't clear why, acid reflux can worsen asthma and asthma can worsen acid reflux (6). However, Chan WW and co-workers, 2011 claimed that gastroesophageal reflux disease occurs frequently among patients with asthma, despite that the therapy with proton pump inhibitors to improve asthma control remains controversial (13). Moreover, two proposed mechanisms involved in the pathogenesis of GERD associated cough: (1) acid in the distal esophagus stimulating an esophageal-tracheobronchial cough reflex, and (2) micro or macroaspiration of esophageal contents into the larynx and tracheobronchial tree. Dual-probe esophageal pH testing 
with $\mathrm{pH}$ electrodes in the proximal and distal esophagus, esophageal acid infusion studies, and evaluation of agents inhibiting cough have added significantly to the understanding of GERD-associated cough (12).

\section{Conclusion:-}

The study concludes that Gastroesophageal reflux associated cough and asthma patients showed an obstructive spirometric pattern irrelevant to the presence or absence of symptoms or duration of the disease. On the other hand, the same obstructive spirometric pattern was reported in those with positive endoscopic findings when they were compared with subjects with negative findings.

\section{References:-}

1. Malfertheiner P, Hallerback B. Clinical manifestations and complications of gastroesophageal reflux disease. Int J Clin Pract., 2005; 59: 346-55.

2. Spechler S. Epidemiology and natural history of gastroesophageal reflux disease. Digestion. 1992; 51 Suppl 1: 24-9.

3. King A, MacDonald C, Örn C. Understanding gastroesophageal reflux disease: a patient cluster analysis Int J Clin Pract., 2008; 62:1838-43.

4. Vakil N, van Zanten S, Kahrilas P, Dent J, Jones R and the Global Consensus Group. The Montreal definition and classification of gastroesophageal reflux disease: a global evidence-based consensus. Am J Gastroenterol., 2006; 101:1900-20.

5. Harding SM. Gastroesophageal reflux: a potential asthma trigger. Immunol Allergy Clin North Am., 2005; 25(1): 131-48.

6. Aras G, Kanmaz D, Kadakal F, Purisa S, Sonmez K, Tunkay E and Ozdimer A. Gastroesophageal reflux disease in our asthma patients ; the presence of dysphagia can influence pulmonary function. Multidisciplinary Respiratory Medicine. 2012; 7:53.

7. Ganong W F. Applied physiology, Good diet: In Review of Medical Physiology, 22nd ed. McGraw Hill, 2005; 310.

8. Standardization of lung function testing: helpful guidance from the ATS/ERS Task Force. Thorax. 2006 September; 61(9): 744-746.

9. Chen Y, Breithaupt K, Muhajarine N. Occurrence of chronic obstructive pulmonary disease among Canadians and sex-related risk factors. J Clin Epidemiol., 2000; 53: 755- 61.

10. Chen Y, Dales R, Tang M, Krewski D. Obesity may increase the incidence of asthma in women but not in men: longitudinal observations from the Canadian National Population Health Surveys. Am J Epidemiol., 2002; 155: $191-7$.

11. Ahmad AF, Yonis, RA, Al-habib HM. Waist circumference: a better predictor for lung ventilation than body mass index. Ann Coll Med Mosul. 2010; 36(1\&2): 12-17.

12. Susan M. Harding, and Joel E. Richter. The Role of Gastroesophageal Reflux in Chronic Cough and Asthma. CHEST 1997; 111: 1389-1402.

13. Chan WW, Chiou E, Obstein KL, Tignor AS, Whitlock TL. The efficacy of proton pump inhibitors for the treatment of asthma in adults: a meta-analysis. Arch Intern Med. 2011 Apr 11; 171(7): 620-9. 